\title{
Supplementary Information for A Spectrum of Exfoliable 1D van der Waals Molecular Wires and Their Electronic Properties
}

\author{
Yanbing Zhu' ${ }^{1}$, Daniel A. Rehn², Evan R. Antoniuk ${ }^{3}$, Gowoon Cheon ${ }^{1}$, Rodrigo Freitas ${ }^{4}$, \\ Aditi Krishnapriyan ${ }^{5}$, Evan J. Reed ${ }^{*}$ \\ 1'Department of Applied Physics, Stanford University, Stanford, California 94305, United States \\ ${ }^{2}$ Computational Physics Division, Los Alamos National Laboratory, Los Alamos, New Mexico \\ ${ }^{3}$ Department of Chemistry, Stanford University, Stanford, California 94305, United States \\ ${ }^{4}$ Department of Materials Science and Engineering, Massachusetts Institute of \\ Technology,Cambridge, Massachusetts 02139, United States \\ ${ }^{5}$ Computational Research Division, Lawrence Berkeley National Laboratory, Berkeley, California \\ 94720, United States \\ ${ }^{6}$ Department of Materials Science and Engineering, Stanford University, Stanford California \\ 94305, United States
}

*E-mail: evanreed@stanford.edu; Phone: (650) 723-2971 
SI Table 1. Largest population common families of previously screened 1D wires and intercalated 1D wires categorized by similarity in geometric structure using the Structure Matcher module of Pymatgen. The structure of the first compound for each family listed is shown. Bolded formulas indicate that DFT calculations in the Materials Project database exhibit a zero electronic band-gap .

\begin{tabular}{|c|c|c|c|}
\hline $\begin{array}{l}\text { Sample Material } \\
\text { Structure }\end{array}$ & $\begin{array}{l}\text { Number of } \\
\text { materials }\end{array}$ & Space group & Materials \\
\hline & 11 & Pnma, 62 & $\begin{array}{c}\text { SbSel, BiSel, SbSI, BiSeBr, SbSBr, BiSI, BiSCl, } \\
\text { BiSBr, SnICl, PbIBr, PbBrCl }\end{array}$ \\
\hline & 10 & Pnma, 62 & $\begin{array}{l}\mathrm{TaTISe}_{3}, \mathrm{CrSbSe}_{3}, \mathrm{CrSbS}_{3}, \mathrm{ZrSnS}_{3}, \mathrm{HfSnS}_{3}, \\
\mathrm{ZrPbS}_{3}, \mathrm{HfPbS}_{3}, \mathrm{InSbS}_{3}, \mathrm{MnInBr}_{3}, \mathrm{MgInBr}_{3}\end{array}$ \\
\hline & 5 & I4/mcm, 140 & InGaTe $_{2}, \mathrm{TIGaTe}_{2}, \mathrm{TIGaSe}_{2}, \mathrm{AITISe}_{2}, \mathrm{TIInSe}_{2}$ \\
\hline & 5 & P6_3/mcm, 193 & $\mathrm{Hfl}_{3}, \mathrm{Nbl}_{3}, \mathrm{TiCl}_{3}, \mathrm{ZrBr}_{3}, \mathrm{ZrCl}_{3}$ \\
\hline & 5 & $\mathrm{C} 2 / \mathrm{m}, 12$ & $\begin{array}{c}\mathrm{CoH}_{4}(\mathrm{BrO})_{2}, \mathrm{CoH}_{4}(\mathrm{ClO})_{2}, \mathrm{MnH}_{4}(\mathrm{BrO})_{2}, \mathrm{FeH}_{4}(\mathrm{ClO})_{2}, \\
\mathrm{MnH}_{4}(\mathrm{ClO})_{2}\end{array}$ \\
\hline
\end{tabular}




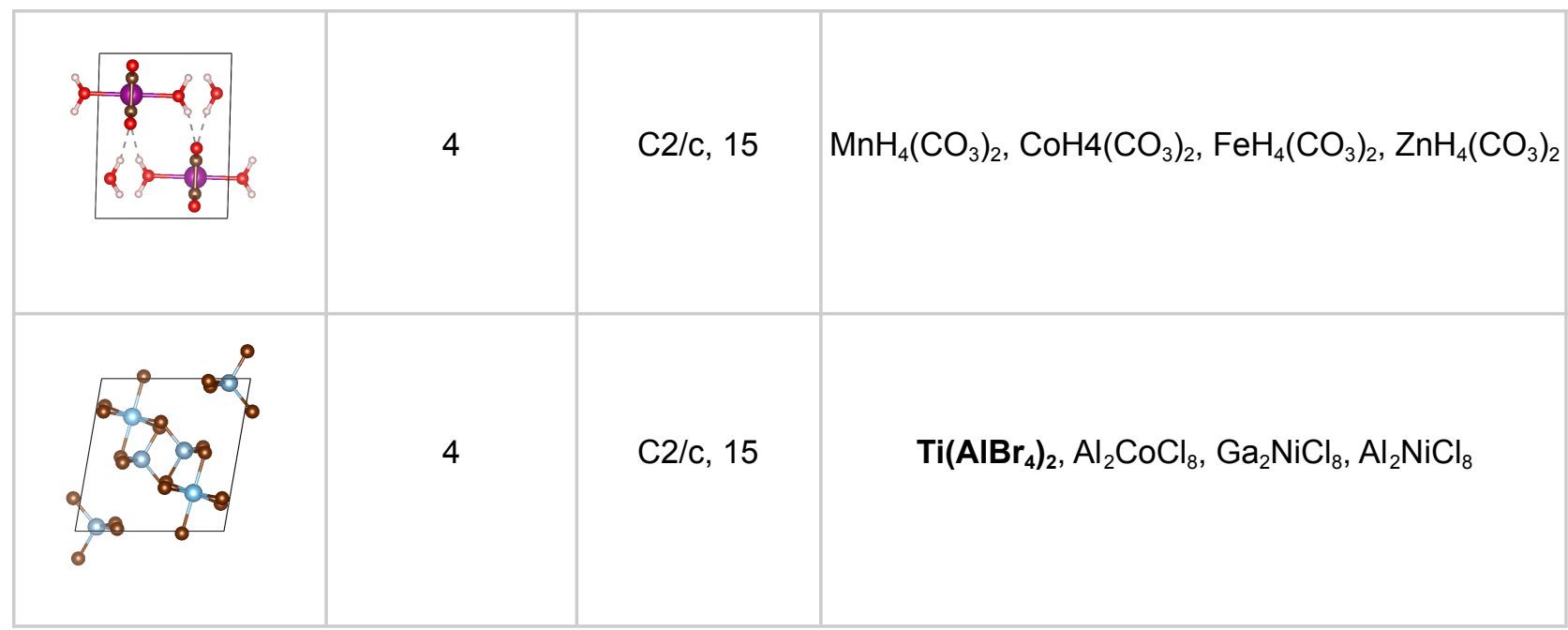

SI Table 2. The Grimme-D3 corrected binding energies, which is a proxy for the exfoliation of a single wire from the bulk structure or exfoliation of a 2D plane of 1D wires from the bulk structure, are shown. Energies using two additional van der Waals corrections, optB88 and vdW-DF2, are presented for select materials for the single wire exfoliation. Energies are presented per formula unit.

\begin{tabular}{|c|c|c|c|c|}
\hline Material & $\begin{array}{c}\text { 1D from bulk } \\
\text { (eV/f.u.) }\end{array}$ & $\begin{array}{c}\text { 2D from bulk } \\
\text { (eV/f.u.) }\end{array}$ & $\begin{array}{c}\text { optB88 energy 1D } \\
\text { from bulk (eV/f.u.) }\end{array}$ & $\begin{array}{c}\text { vdW-DF2 energy } \\
\text { 1D from bulk } \\
\text { (eV/f.u.) }\end{array}$ \\
\hline $\mathrm{Hfl}_{3}$ & -0.58 & -0.37 & -1.78 & -0.51 \\
\hline $\mathrm{Sb}_{2} \mathrm{Se}_{3}$ & -1.11 & -0.70 & -- & -- \\
\hline $\mathrm{RuCl}_{3}$ & -0.36 & $\mathrm{~N} / \mathrm{A}$ & -- & -- \\
\hline $\mathrm{GeTe}$ & -0.43 & -0.13 & -- & -- \\
\hline $\mathrm{Ta}_{2} \mathrm{Pd}_{3} \mathrm{Se}_{8}$ & -2.76 & -3.56 & -- & -- \\
\hline $\mathrm{NbSe}_{3}$ & -2.85 & -- & -- & -- \\
\hline $\mathrm{SbSI}$ & -0.59 & -0.53 & - & -- \\
\hline $\mathrm{GePdS}_{3}$ & -0.50 & -0.37 & -- & -- \\
\hline $\mathrm{ZrTe}_{3}$ & -2.50 & -2.83 & -- & -0.23 \\
\hline $\mathrm{ZrTe}_{5}$ & -2.04 & -0.54 & -0.53 & -0.14 \\
\hline $\mathrm{Se}$ & -0.24 & - & - & - \\
\hline
\end{tabular}




\begin{tabular}{|c|c|c|c|c|}
\hline Te & -0.46 & -0.24 & -0.62 & -0.30 \\
\hline SbSel & -0.59 & -0.54 & -1.39 & -0.52 \\
\hline $\mathrm{PdBr}_{2}$ & -0.51 & -0.211 & -0.51 & -0.40 \\
\hline $\mathrm{BiSel}$ & -0.64 & -- & -- & - \\
\hline $\mathrm{BiSl}$ & -0.63 & -- & -- & - \\
\hline $\mathrm{PNF}_{2}$ & -0.20 & -0.14 & -1.06 & -0.25 \\
\hline
\end{tabular}

The 1D exfoliation energies are calculated using the relationship

$$
\left[E_{\text {bulk }}-\left(N_{b u l k} / N_{1 D}\right) * E_{1 D}\right] / f \cdot u_{\text {bulk }}
$$

where $E_{b u l k}$ is the total energy of the bulk structure, and $E_{1 D}$ is the total energy of the 1D structure. $N_{b u l k}$ and $N_{1 D}$ are the number of wires units in the bulk and isolated structures respectively, and $f . u_{\text {. }}$.ulk is the number of formula units present in the bulk structure.

The 2D exfoliation energies are calculated analogously as

$$
\left[E_{\text {bulk }}-\left(N_{\text {bulk }} / N_{2 D}\right) * E_{2 D}\right] / f \cdot u_{\text {bulk }}
$$

where $E_{2 D}$ and $N_{2 D}$ are the total energy and the number of wire units in the two-dimensional plane of 1D wires, respectively.

SI Table 3a. The Grimme-D3 corrected energies from DFT calculations for the bulk, 2D plane of wires, and individual wires alongside related quantities for calculating the binding energies. In addition, for the exfoliation of $2 \mathrm{D}$ layers, the energy in terms of $\mathrm{eV} / \mathrm{A}^{2}$ is provided.

\begin{tabular}{|c|c|c|c|c|c|c|c|c|c|}
\hline & $\begin{array}{c}\text { Bulk } \\
\text { energy } \\
(\mathbf{e V})\end{array}$ & $\begin{array}{c}\text { 2D energy } \\
(\mathbf{e V})\end{array}$ & $\begin{array}{c}\text { 1D energy } \\
(\mathbf{e V})\end{array}$ & $\begin{array}{c}\text { Formula } \\
\text { units } \\
\text { (Bulk) }\end{array}$ & $\begin{array}{c}\text { Formula } \\
\text { units (2D) }\end{array}$ & $\begin{array}{c}\text { Formula } \\
\text { units (1D) }\end{array}$ & $\begin{array}{c}\text { Wires } \\
\text { (bulk, 2D, } \\
\text { 1D) }\end{array}$ & Area (A $\left.^{2}\right)$ & eV/A $^{2}$ \\
\hline $\mathrm{Sb}_{2} \mathrm{Se}_{3}$ & -339.79 & -82.13 & -40.26 & 16 & 4 & 2 & $8,2,1$ & 91.991 & 0.123 \\
\hline $\mathrm{GeTe}$ & -255.57 & -62.88 & -15.12 & 32 & 8 & 2 & $16,4,1$ & 89.691 & 0.045 \\
\hline $\mathrm{ZrTe}_{5}$ & -459.62 & -112.76 & -26.68 & 8 & 4 & 1 & $8,4,1$ & 45.688 & 5.124 \\
\hline $\mathrm{Se}$ & -44.43 & -21.38 & -10.38 & 4 & 2 & 1 & $12,6,3$ & 42.878 & 0.039 \\
\hline $\mathrm{Te}$ & -40.88 & -18.98 & -8.84 & 4 & 2 & 1 & $12,6,3$ & 52.539 & 0.056 \\
\hline $\mathrm{PdBr}_{2}$ & -162.6 & -39.8 & -19.31 & 16 & 4 & 2 & $8,2,1$ & 51.778 & 0.066 \\
\hline
\end{tabular}




\begin{tabular}{|c|c|c|c|c|c|c|c|c|c|}
\hline SbSel & -172.79 & -41.05 & -20.41 & 16 & 4 & 2 & $8,2,1$ & 88.495 & 0.097 \\
\hline $\mathrm{PNF}_{2}$ & -394.16 & -97.99 & -48.87 & 16 & 4 & 2 & $8,2,1$ & 53.446 & 0.041 \\
\hline $\mathrm{GePdS}_{3}$ & -400.55 & -98.67 & -49.07 & 16 & 4 & 2 & $8,2,1$ & 63.755 & 0.092 \\
\hline $\mathrm{ZrTe}_{3}$ & -175.34 & -76.37 & -19.42 & 8 & 4 & 1 & $8,4,1$ & 45.688 & 0.495 \\
\hline $\mathrm{SbSI}$ & -182.27 & -43.44 & -21.61 & 16 & 4 & 2 & $8,2,1$ & 84.655 & 0.101 \\
\hline $\mathrm{Hfl}_{3}$ & -151 & -73.4 & -36.60 & 8 & 4 & 2 & $4,2,1$ & 91.518 & 0.046 \\
\hline
\end{tabular}

SI Table 3b. Local Density Approximation (LDA) calculations are performed for the same prototype wire structures-as in SI Table 2. TThe Grimme-D3 energies from SI Table 2 are included, indicating qualitative agreement with the LDA calculations.

\begin{tabular}{|c|c|c|c|c|}
\hline Material & $\begin{array}{c}\text { LDA energy 1D } \\
\text { from bulk (eV/f.u.) }\end{array}$ & $\begin{array}{c}\text { Bulk LDA energy } \\
\text { (eV/calculation } \\
\text { cell) }\end{array}$ & $\begin{array}{c}\text { 1D LDA energy } \\
\text { (eV/calculation } \\
\text { cell) }\end{array}$ & $\begin{array}{c}\text { Grimme-D3 1D } \\
\text { from bulk (eV/f.u) }\end{array}$ \\
\hline $\mathrm{Se}$ & -0.309 & -49.92 & -11.55 & -0.24 \\
\hline $\mathrm{Te}$ & -0.464 & -45.65 & -10.02 & -0.46 \\
\hline $\mathrm{SbSel}$ & -0.565 & -191.07 & -22.75 & -0.51 \\
\hline $\mathrm{PdBr}_{2}$ & -0.337 & -185.22 & -22.48 & -0.50 \\
\hline $\mathrm{GePdS}_{3}$ & -0.308 & -441.00 & -54.51 & -0.20 \\
\hline $\mathrm{PNF}_{2}$ & -0.166 & -432.08 & 53.68 & -0.58 \\
\hline $\mathrm{Hfl}_{3}$ & -0.458 & -162.21 & -39.64 & \\
\hline
\end{tabular}




\section{Band-structures}

\section{$\mathrm{Hfl}_{3}$}
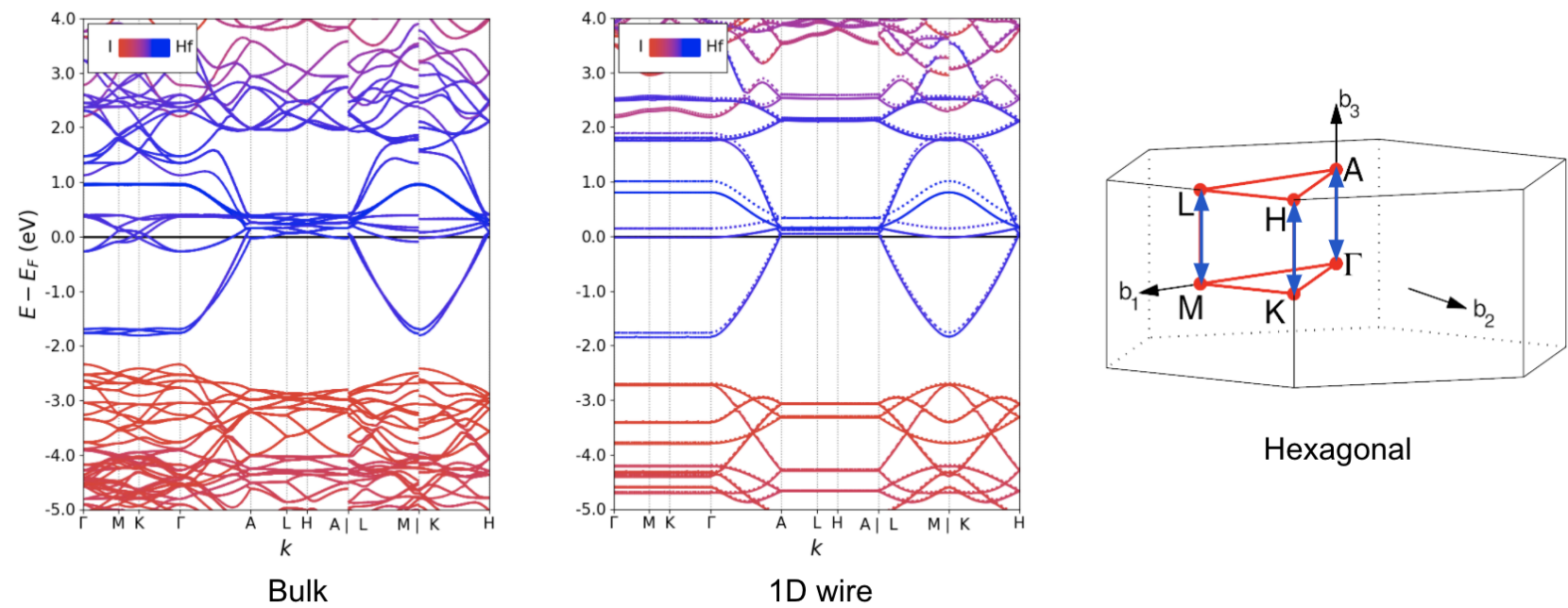

Hexagonal

\section{$\mathrm{PdBr}_{2}$}
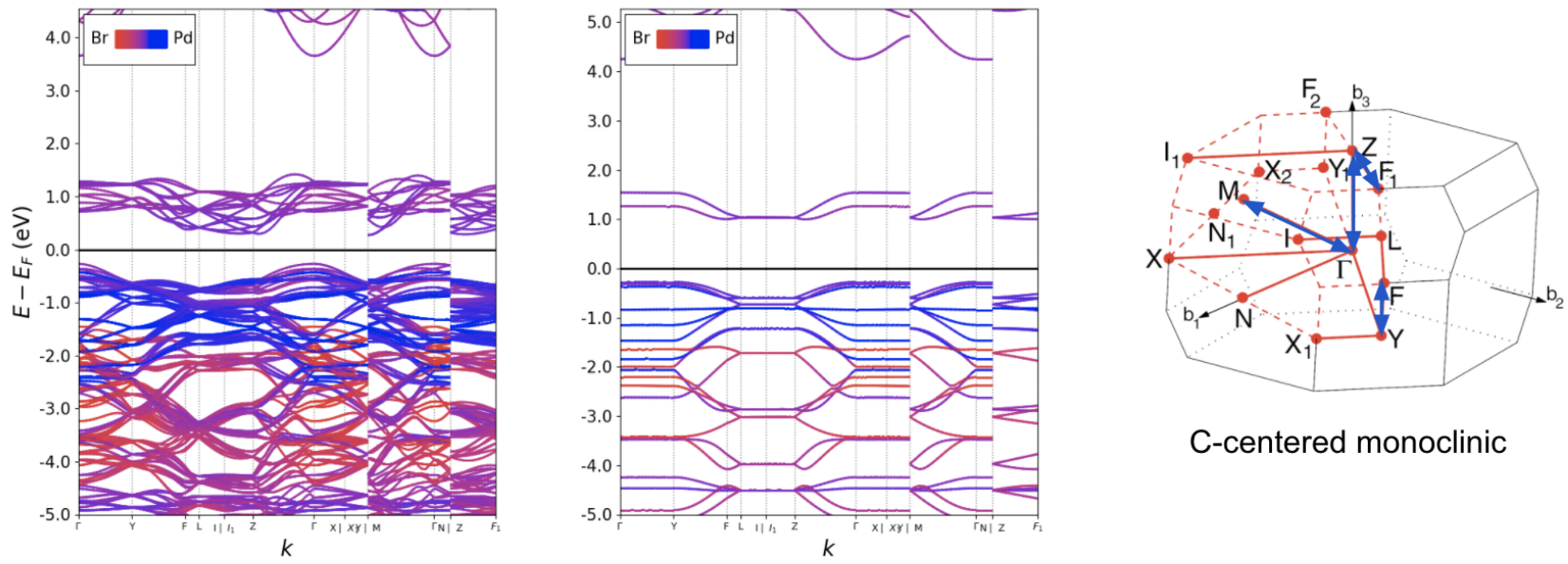

Bulk

1D wire 


\section{SbSel}

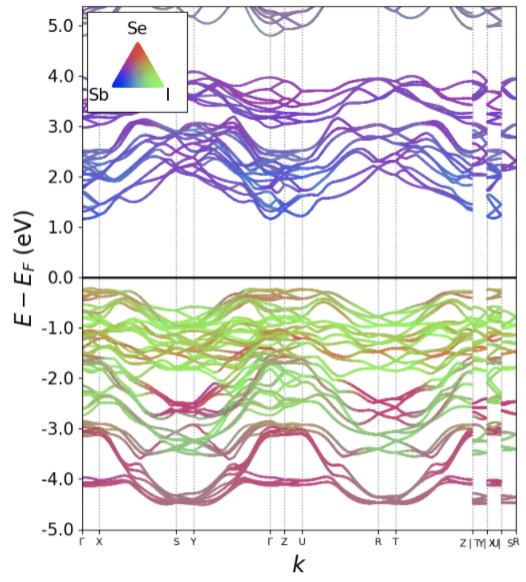

Bulk

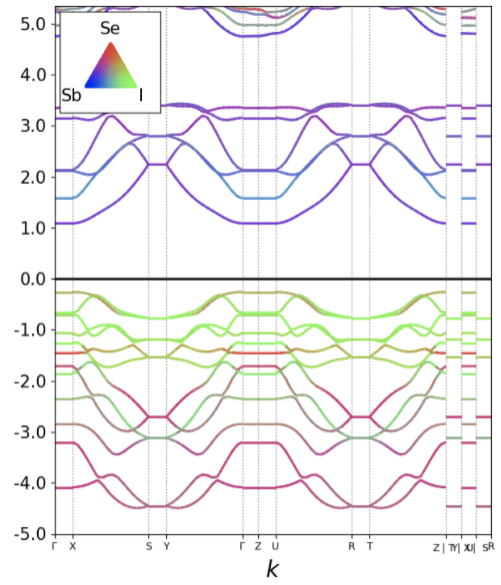

1D

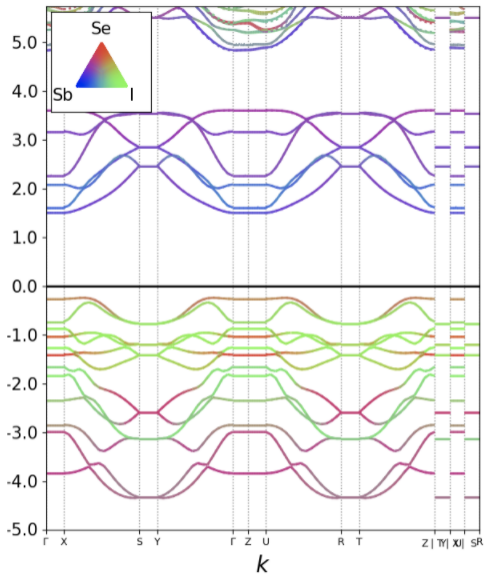

1D (relaxed)

\section{$\mathrm{PNF}_{2}$}

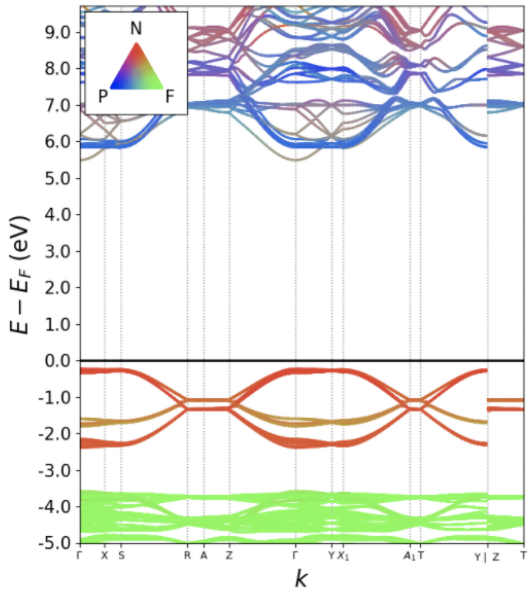

Bulk

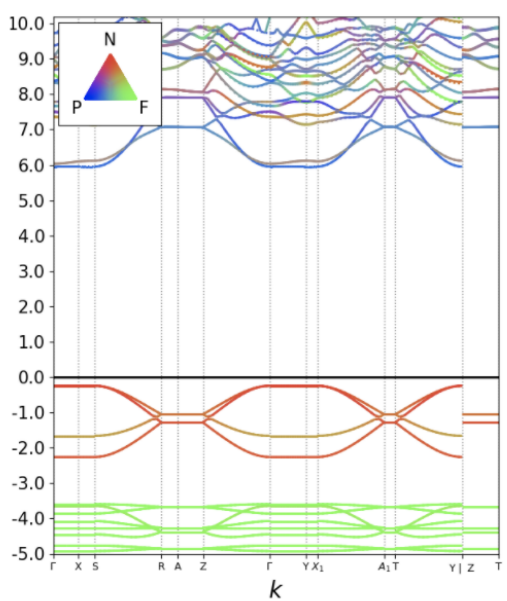

1D wire

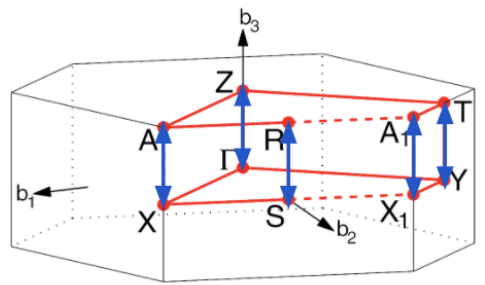

C-centered orthorhombic 


\section{$\mathrm{GePdS}_{3}$}

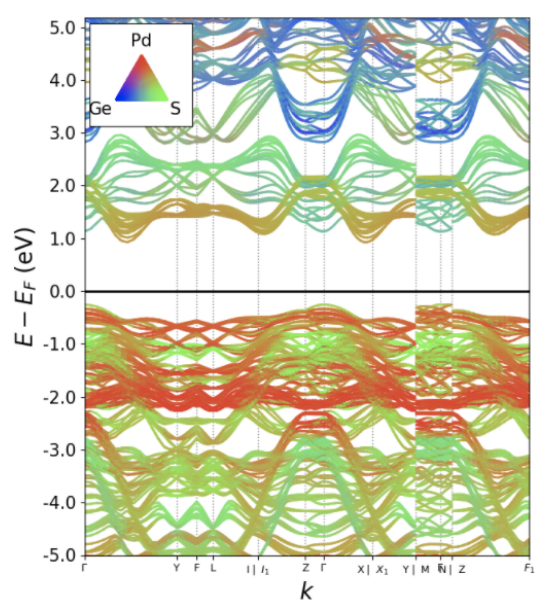

Bulk

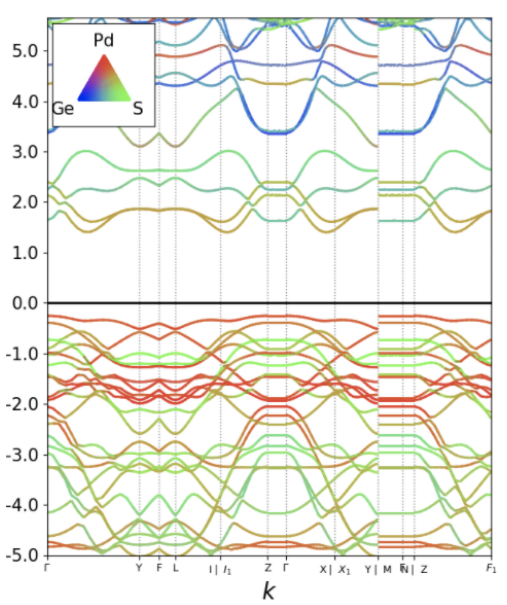

1D wire

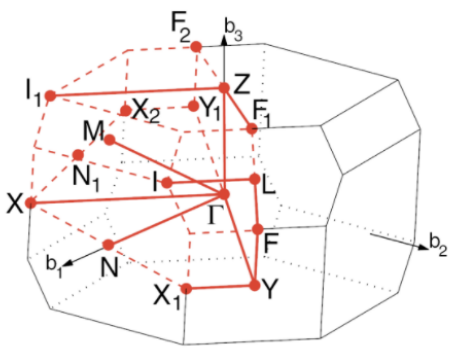

C-centered monoclinic

\section{Heterostructure $\mathrm{Sb}_{6} \mathrm{O}_{5} \mathrm{~F}_{8}$}
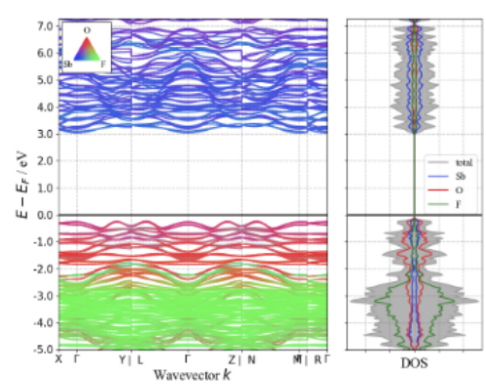

Joint

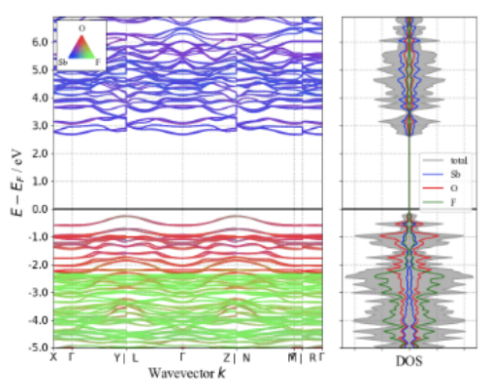

SbOF
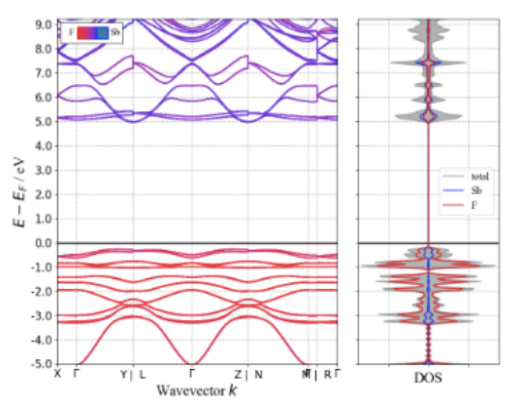

$\mathrm{SbF}_{3}$ 


\section{Heterostructure $\mathrm{Te}_{7} \mathrm{As}_{5} \mathrm{I}$}

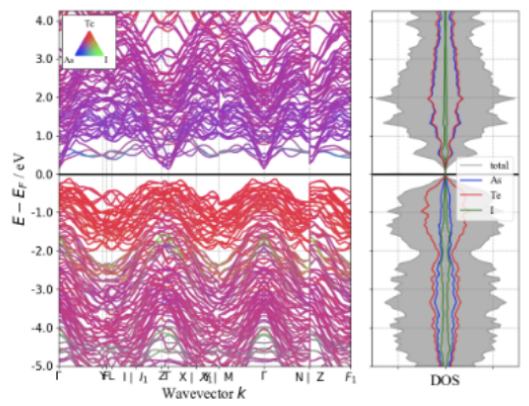

Joint

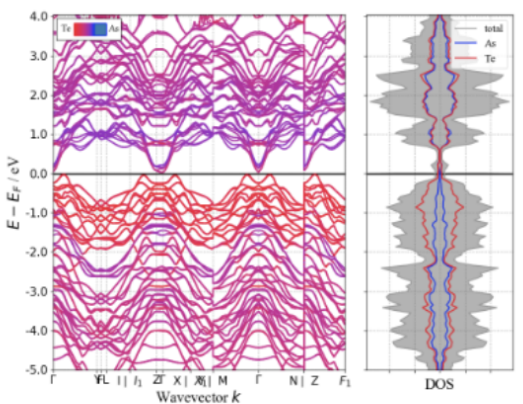

$\mathrm{As}_{2} \mathrm{Te}_{3}$

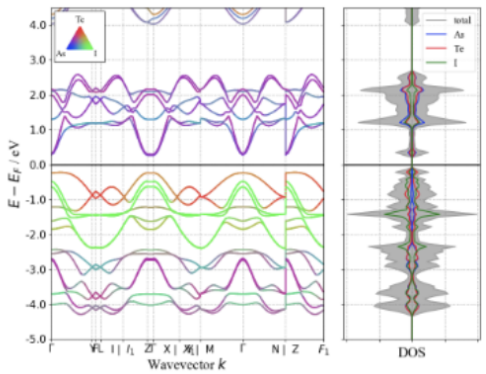

AsTel

SI Figure 1.1 The spin-polarized band-structures for the bulk and the single wire case are presented for selected materials studied. The elemental contribution to the band-structure remains relatively consistent from the bulk structure to individual 1D wire structure. The Brillouin zone is shown for reference generated using [2], and the wire direction in reciprocal space is shown for structures where the wire is along few high-symmetry paths. For band structures of the isolated wire with vacuum spacing in the unit cell, the only unique portion is along the wire axis. The wire axis is along Gamma and a for $\mathrm{Hfl}_{3}, \mathrm{Gamma}$ to $\mathrm{Z}$ for $\mathrm{PdBr}_{2}$, Gamma to $\mathrm{Y}$ for SbSel, Gamma to $\mathrm{Z}$ fo $\mathrm{PNF}_{2}$, and Gamma to $\mathrm{Y}$ for $\mathrm{GePdS}$, Gamma to $\mathrm{M}$ for $\mathrm{Sb}_{6} \mathrm{O}_{5} \mathrm{~F}_{8}$, and Gamma to $\mathrm{Z}$ for $\mathrm{Te}_{7} \mathrm{As}_{5}$. The remainder of the band structure is either equivalent to this portion or flat bands due to minimal or no interaction between adjacent wires separated by vacuum. Additional details and the Brillouin zone for SbSel are in the figure below. The band-structures of the two selected heterostructure materials and their sub-components are also displayed, indicating one component dominates the band contribution. 

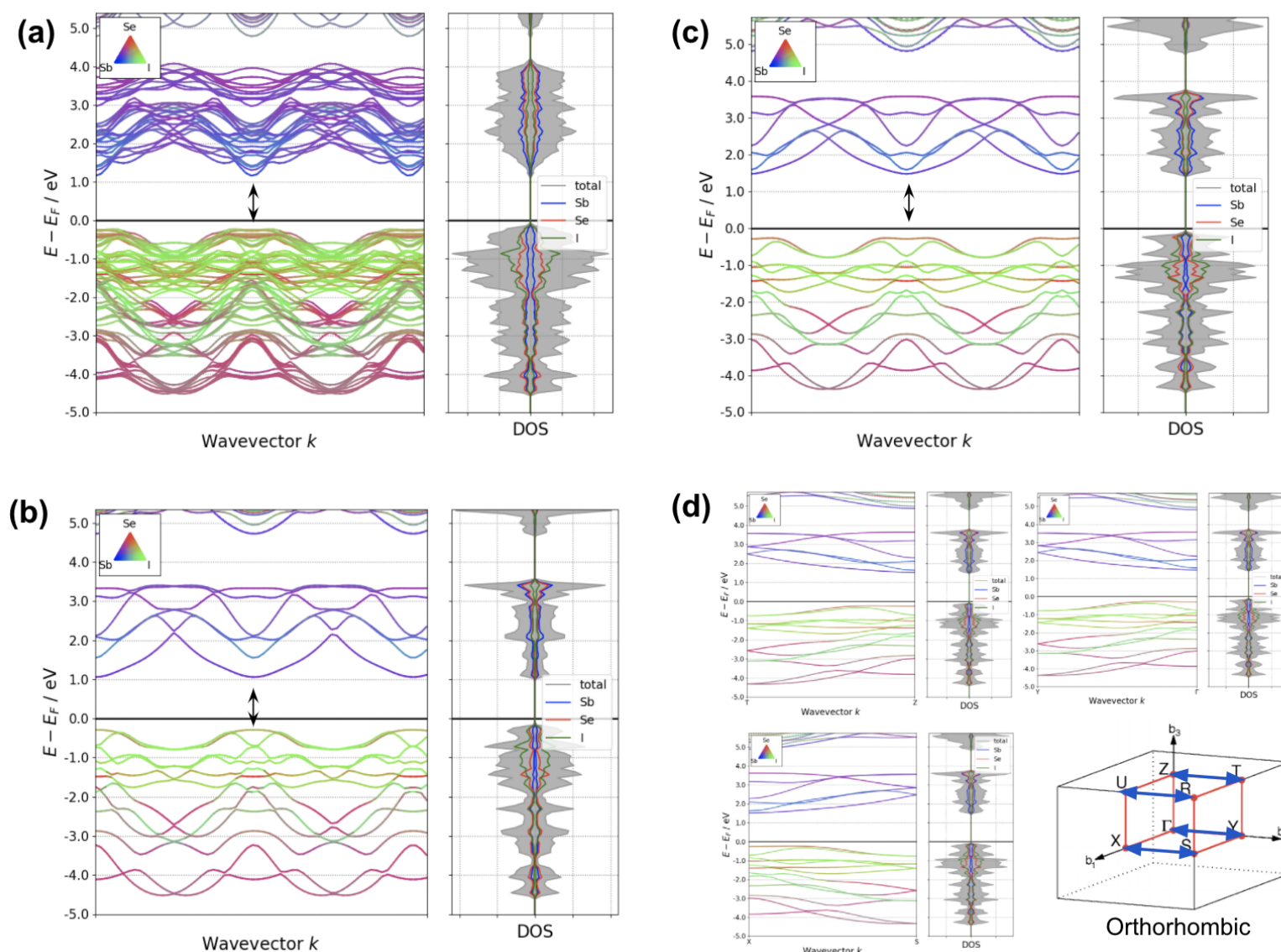

(d)

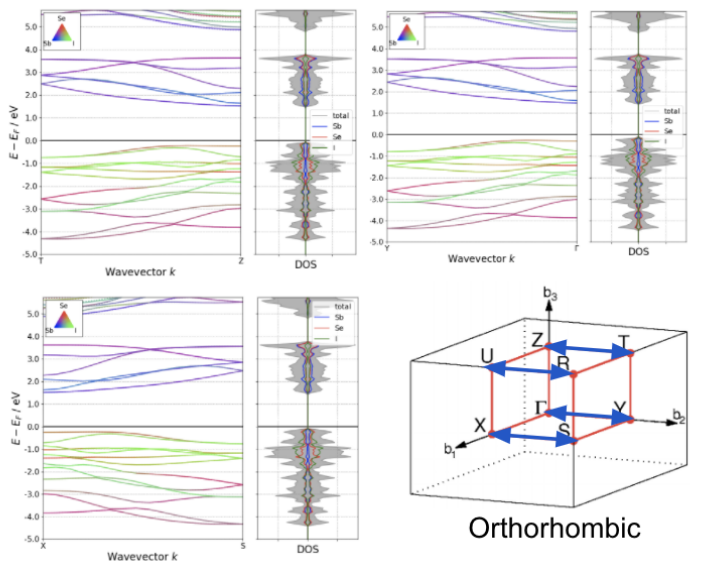

SI Figure 1.2. For the SbSel material with the potential indirect-direct band-gap transitions upon exfoliation of 1D wires, additional calculations are shown. The band-structures of the bulk material, 1D wire form, and relaxed 1D wire form are shown in (a), (b), and (c) respectively along the real-space direction of the wire instead of the high-symmetry lines in reciprocal space. The bulk has an indirect band-gap of $1.393 \mathrm{eV}(1.408 \mathrm{eV}$ direct), and the 1D unrelaxed wire has a direct band-gap of $1.346 \mathrm{eV}$. The $1 \mathrm{D}$ relaxed structure has an indirect band-gap of $1.743 \mathrm{eV}(1.766 \mathrm{eV}$ direct). As the real-space wire direction maps to the T-Z, $\Gamma$-Y and X-S directions in reciprocal space, the band-structures along those paths for the relaxed wire are shown in (d) with the orthorhombic Brillouin zone for reference. The band-gaps are found to be identical to each other and those calculated in the real space wire direction, as is expected for wires surrounded by vacuum with periodic boundary conditions. 


\section{Van der Waals contribution to Inter-wire binding energy}

The percentage of van der Waals contribution can also be considered as a percentage of the inter-wire energy instead of as a percentage of the total energy. This quantity is calculated by

$$
\left[E_{v d w, b u l k}-\left(N_{b u l k} / N_{1 D}\right) * E_{v d w, 1 D}\right] /\left[E_{v d w, b u l k}-\left(N_{1 D}\right) * E_{v d w, 1 D} * f . u\right.
$$

where $f . u$ stands for the number of formulas units present in each unit cell of the bulk structure.

The same can be calculated for the $2 \mathrm{D}$ case in which we consider the inter-wire binding energy between 2D planes composed of $1 \mathrm{D}$ wires. We note that likely due to the nature of the discrete cut-off values for calculating van der Waals energies employed for the D3-Grimme corrections, this percentage has the potential to be slightly above 1 for certain materials. However, the analysis indicates the dominant contribution to the inter-wire binding energy is van der Waals of nature. We can investigate the relationship between the van der Waals percentage of binding energy between 1D wires versus between 2D layers of 1D wires as shown in SI Figure 2, and we find that there is roughly linear correlation. This is reflective of the fact that the spacing between wires in a 2D layer is similar to the spacing between individual 1D wires. 


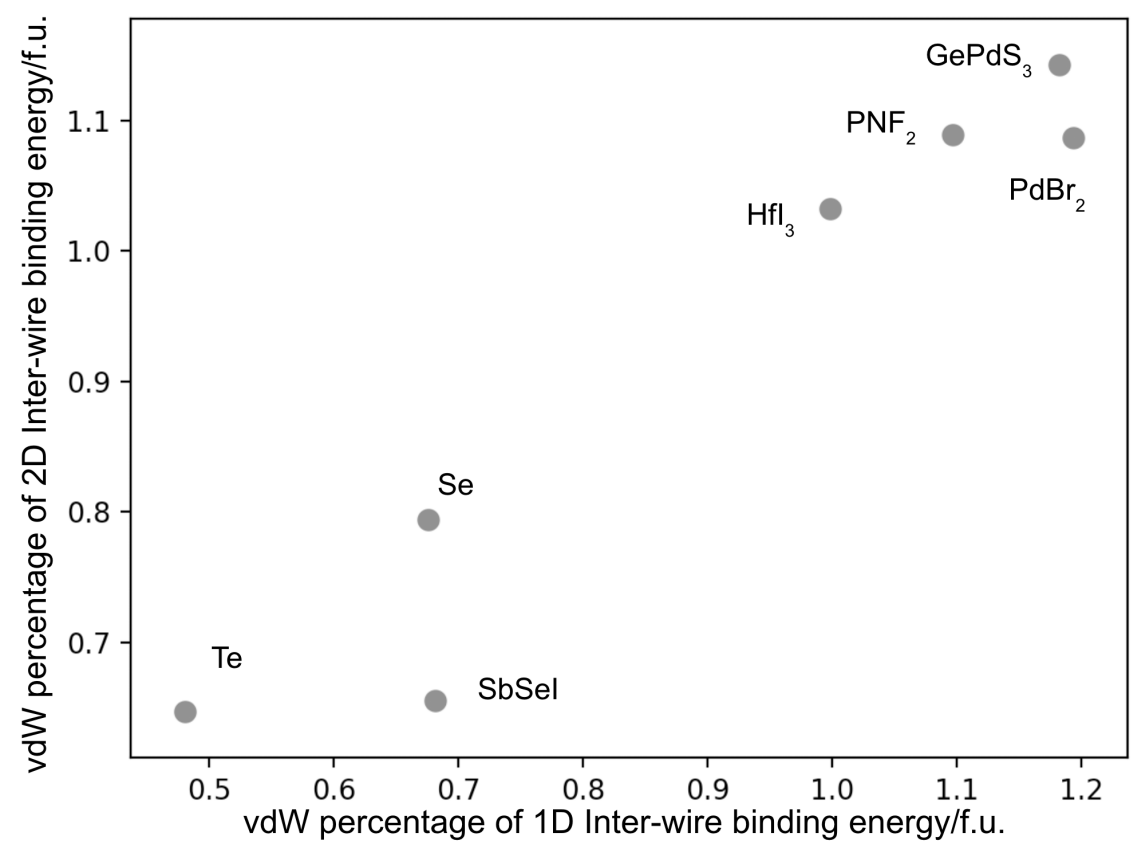

SI Figure 2. The van der Waals D3 correction component of the total Inter-wire binding energy (PBE+D3) is compared for individual $1 \mathrm{D}$ wires and 2D planes of $1 \mathrm{D}$ wires. Higher values indicate vdW bonding is more dominant. Proximity of the data to the line $y=x$ suggests minimal anisotropy in the interwire vdW binding component.

\section{Comparison to common 2D material binding energies}

An explicit comparison to the binding energies of 2D materials can be made by comparing the energies required to exfoliate a $2 \mathrm{D}$ plane of $1 \mathrm{D}$ materials, as there is no suitable length-based comparison for the 1D wire case. We find that the 2D plane exfoliation energies are fairly comparable to those of known exfoliated 2D materials, and below the cutoff threshold of $130 \mathrm{meV}^{-2}$ used in Mounet et. al. [1], with the exception of the $\mathrm{ZrTe}_{5}$. The exfoliation energy of known 2D materials are also often reported in terms of formula units, but this is not completely analogous as the unit cells for 1D materials are typically much larger than that of common 2D layered materials, hence appearing larger when energy per formula unit is directly compared. 


\section{SbSel Cluster Calculations}

To elucidate a possible indirect-direct band-gap change in the SbSel family upon exfoliation of 1D wires, we have further performed calculations of clusters with different number of wire components, aside from the bulk, 2D sheet of 1D wires, and individual 1D wire structure. From the same $2 \times 1 \times 2$ supercell structure used for the bulk, 2D sheet, and 1D wire calculations, we extract components with 2,3 , and 5 clusters. Vacuum padding was added in the $a$ and $c$ directions perpendicular to the wire chain.

(a)

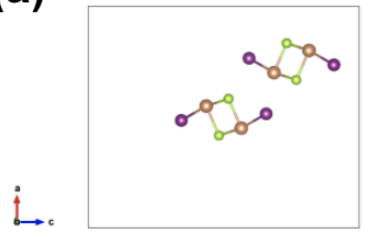

Cluster Variant 1 (b)

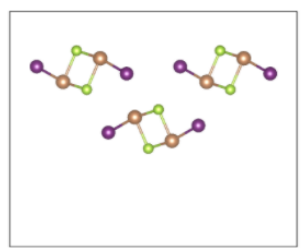

Cluster Variant 2 (c)

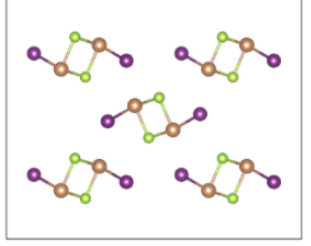

Cluster Variant 3

SI Figure 3. The different sized cluster variants for which additional calculations were performed, omitting the additional vacuum added for clarity. 
SI Table 4. The resulting band-structure results for different cluster variants of the material SbSel. Cluster 1-3 contains 2,3 , and 5 wire structures respectively. Calculations were performed with no relaxation from the bulk structure and relaxations with both the unit cell volume held constant versus free, and with padded vacuum values of 5,10 , and $20 \AA$. These results suggest that unrelaxed clusters of wires generally give slightly direct band-gaps, while relaxed clusters give indirect transitions. If the transition is direct, there will be an indirect to direct transition upon exfoliation from bulk. However, the accuracy of these calculations combined with potential screening effects of the substrate and electron-hole interactions (excitons) is probably not sufficient to discern these two cases.

\begin{tabular}{|c|c|c|c|c|c|c|c|c|}
\hline Type & $\begin{array}{c}\text { Vacuum } \\
\text { (A) }\end{array}$ & Relaxed & Band-gap & Direct & Transition & E-fermi & VBM & CBM \\
\hline \multirow[t]{3}{*}{ Cluster 1} & 20 & No & 0.901 & Yes & $\Gamma-\Gamma$ & -4.717 & -4.948 & -4.047 \\
\hline & 20 & Yes & 1.216 & No & $(0.5,0.133,0)-\Gamma$ & -4.672 & -4.921 & -3.704 \\
\hline & 20 & $\begin{array}{l}\text { Yes (fixed } \\
\text { volume) }\end{array}$ & 1.201 & No & $(0.5,0.133,0)-\Gamma$ & -4.670 & -4.930 & -3.730 \\
\hline \multirow[t]{3}{*}{ Cluster 2} & 20 & No & 0.661 & Yes & $\Gamma-\Gamma$ & -4.200 & -4.493 & -3.832 \\
\hline & 20 & Yes & 0.950 & No & $(0.5,0.133,0)-\Gamma$ & -4.201 & -4.466 & -3.516 \\
\hline & 20 & $\begin{array}{l}\text { Yes (fixed } \\
\text { volume) }\end{array}$ & 0.966 & No & $(0.5,0.133,0)-\Gamma$ & -4.219 & -4.499 & -3.533 \\
\hline \multirow[t]{3}{*}{ Cluster 3} & 20 & No & 0.780 & Yes & $\Gamma-\Gamma$ & -3.806 & -4.050 & -3.207 \\
\hline & 20 & Yes & 1.102 & No & $(0.5,0.133,0)-\Gamma$ & -3.720 & -4.000 & -2.90 \\
\hline & 20 & $\begin{array}{c}\text { Yes (fixed } \\
\text { volume) }\end{array}$ & 0.126 & No & $(0.5,0.133,0)-\Gamma$ & -3.7670 & -3.808 & -3.682 \\
\hline
\end{tabular}

\begin{tabular}{|c|c|c|c|c|c|c|c|c|}
\hline Type & $\begin{array}{c}\text { Vacuum } \\
(\mathbf{A})\end{array}$ & Relaxed & Band-gap & Direct & Transition & E-fermi & VBM & CBM \\
\hline Cluster 1 & 5 & No & 0.924 & Yes & $\Gamma-\Gamma$ & -3.872 & -4.111 & -3.187 \\
\cline { 2 - 9 } & 10 & No & 0.911 & Yes & $\Gamma-\Gamma$ & -4.289 & -4.529 & -3.618 \\
\cline { 2 - 8 } & 5 & Yes & 1.234 & No & $(0.5 .0 .133,0)-\Gamma$ & -3.812 & -4.076 & -2.842 \\
\hline
\end{tabular}




\begin{tabular}{|c|c|c|c|c|c|c|c|c|}
\hline \multirow[t]{3}{*}{ Cluster 2} & 5 & No & 0.7241 & Yes & $\Gamma-\Gamma$ & -3.004 & -3.230 & -2.506 \\
\hline & 10 & No & 0.688 & Yes & $\Gamma-\Gamma$ & -3.636 & -3.861 & -3.174 \\
\hline & 5 & Yes & 0.997 & Yes & $(0.5,0.133,0)-\Gamma$ & -2.915 & -3.170 & -2.173 \\
\hline \multirow[t]{3}{*}{ Cluster 3} & 5 & No & 0.814 & No & $(0,0,0.100)-\Gamma$ & -1.678 & -1.941 & -1.127 \\
\hline & 10 & No & 0.688 & Yes & $\Gamma-\Gamma$ & -3.636 & -3.862 & -3.174 \\
\hline & 5 & Yes & 1.087 & No & $\begin{array}{c}(0.5,0.1,0)-(0.33 \\
3,0,0)\end{array}$ & -1.47 & -1.748 & -0.662 \\
\hline
\end{tabular}




\section{Geometries}

SI Table 5. The lattice parameters, lattice angles, and space group symmetry of the bulk materials are given. The values are extracted from the DFT relaxed structure using the D3-Grimme van der Waals correction. For reference, the corresponding experimental ICSD numbers and structure parameters are provided for non-supercell geometry. For materials where multiple ICSD numbers exist, the parameters for the first entry are shown.

\begin{tabular}{|c|c|c|c|c|c|c|c|}
\hline Material & $\begin{array}{c}\text { Lattice } \\
\text { parameters } \\
(\mathbf{a}, \mathbf{b}, \mathbf{c})\end{array}$ & $\begin{array}{c}\text { Lattice } \\
\text { angles } \\
(\alpha, \beta, \gamma)\end{array}$ & $\begin{array}{l}\text { Space } \\
\text { group } \\
\text { number }\end{array}$ & $\begin{array}{l}\text { Space group } \\
\text { symmetry }\end{array}$ & ICSD Number & 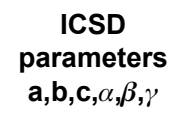 & $\begin{array}{l}\text { ICSD space } \\
\text { group }\end{array}$ \\
\hline $\mathrm{Hfl}_{3}$ & $\begin{array}{c}7.333,7.333 \\
6.432\end{array}$ & $\begin{array}{c}90.0,90.0 \\
120.0\end{array}$ & 193 & P6_3/mcm & 23947 & $\begin{array}{c}7.225,7.225 \\
6.59 \\
90,90,120\end{array}$ & $\underset{(193)}{P 6 \_3 / m c m}$ \\
\hline $\mathrm{Sb}_{2} \mathrm{Se}_{3}$ & $\begin{array}{c}12.058 \\
4.019,11.446\end{array}$ & $\begin{array}{c}90.0,90.0 \\
90.0\end{array}$ & 62 & Pnma & $\begin{array}{c}194836, \\
194837, \\
16680, \\
651516, \\
651519, \\
651518, \\
651521 \\
651515, \\
171569 \\
85676,30973\end{array}$ & $\begin{array}{c}11.805 \\
3.9877 \\
11.6623 \\
90,90,90\end{array}$ & Pnma (62) \\
\hline $\mathrm{RuCl}_{3}$ & $\begin{array}{c}6.143,6.143 \\
5.622\end{array}$ & $\begin{array}{c}90.0,90.0 \\
90.0\end{array}$ & 193 & P6_3/mcm & $\begin{array}{c}25771,22090 \\
22092 \\
414041 \\
414040\end{array}$ & $\begin{array}{c}6.125,6.125 \\
5.653 \\
90,90,120\end{array}$ & $\begin{array}{c}\text { P6_3/mcm } \\
(193)\end{array}$ \\
\hline GeTe & $\begin{array}{c}12.866 \\
10.988,4.081\end{array}$ & $\begin{array}{c}90.0,90.0 \\
90.0\end{array}$ & 60 & Pbcn & 56604 & $\begin{array}{c}7.441,7.678 \\
5.435 \\
90,90,90\end{array}$ & Pbcn (60) \\
\hline $\mathrm{Ta}_{2} \mathrm{Pd}_{3} \mathrm{Se}_{8}$ & $\begin{array}{c}21.177 \\
30.416,3.574\end{array}$ & $\begin{array}{c}90.0,90.0 \\
90.0\end{array}$ & 55 & Pbam & 73318 & $\begin{array}{c}15.152 \\
10.631,3.540 \\
90,90,90\end{array}$ & Pbam (55) \\
\hline $\mathrm{NbSe}_{3}$ & $\begin{array}{c}9.676,3.355 \\
14.657\end{array}$ & $\begin{array}{c}90.0 \\
108.65 \\
90.0\end{array}$ & 11 & P2_1/m & $\begin{array}{c}645384, \\
76579 \\
600618 \\
30002\end{array}$ & $\begin{array}{c}\text { 10.02, } 3.47 \\
15.63 \\
90,109.5,90\end{array}$ & P2_1/m (11) \\
\hline SbSI & $\begin{array}{c}8.675,4.112 \\
10.294\end{array}$ & $\begin{array}{c}90.0,90.0 \\
90.0\end{array}$ & 62 & Pnma & $\begin{array}{l}28265,85301 \\
28264,26923 \\
25572,28305\end{array}$ & $\begin{array}{c}8.54,10.18 \\
4.12 \\
90,90,90\end{array}$ & Pnma (62) \\
\hline $\mathrm{GePdS}_{3}$ & $\begin{array}{c}14.296 \\
3.491,9.131\end{array}$ & $\begin{array}{c}90.0 \\
107.52 \\
90.0\end{array}$ & 12 & $\mathrm{C} 2 / \mathrm{m}$ & 408505 & $\begin{array}{c}14.217,3.453 \\
9.079 \\
90,106.58 \\
90\end{array}$ & $\mathrm{C} 2 / \mathrm{m}(12)$ \\
\hline
\end{tabular}




\begin{tabular}{|c|c|c|c|c|c|c|c|}
\hline $\mathrm{ZrTe}_{3}$ & $\begin{array}{c}5.944,3.918 \\
10.541\end{array}$ & $\begin{array}{c}90.0 \\
96.694, \\
90.0\end{array}$ & 11 & $\mathrm{P} 2 \_1 / \mathrm{m}$ & $\begin{array}{c}71033,51004, \\
42076, \\
653232, \\
653211, \\
86763,86764\end{array}$ & $\begin{array}{c}5.8948, \\
3.9264 \\
10.104 \\
90,97.93,90\end{array}$ & P2_1/m (11) \\
\hline $\mathrm{ZrTe}_{5}$ & $\begin{array}{l}4.035 \\
14.802 \\
13.579\end{array}$ & $\begin{array}{c}90.0,90.0 \\
90.0\end{array}$ & 63 & $\mathrm{Cmcm}$ & $\begin{array}{c}602282, \\
653212, \\
653228, \\
85507, \\
657473, \\
85506\end{array}$ & $\begin{array}{c}3.99,14.5 \\
13.73,90,90 \\
90\end{array}$ & Cmcm (63) \\
\hline $\mathrm{Se}$ & $\begin{array}{c}4.189,4.189 \\
5.118\end{array}$ & $\begin{array}{c}90.0,90.0 \\
120.0\end{array}$ & 152 & P3_121 & $\begin{array}{c}164265, \\
23073, \\
164262, \\
23069, \\
651846, \\
164264, \\
164271, \\
40018, \\
164270, \\
22251,23071, \\
40016, \\
651852, \\
164269, \\
53801,23068, \\
164268, \\
164266, \\
164267, \\
23070, \\
200685, \\
164263, \\
659253, \\
23072, \\
164261, \\
426974, \\
651850\end{array}$ & $\begin{array}{c}4.046,4.046 \\
5.091,90,90 \\
120\end{array}$ & P3_121 (152) \\
\hline $\mathrm{Te}$ & $\begin{array}{c}4.414,4.414 \\
5.951\end{array}$ & $\begin{array}{c}90.0,90.0 \\
120.0\end{array}$ & 152 & P3_121 & $\begin{array}{c}40008, \\
426980, \\
653045, \\
40042,23065, \\
653047, \\
161690, \\
23067,23059, \\
65692,23060, \\
96502,76150, \\
23058,23062, \\
23061,23066, \\
23064,40041, \\
23063\end{array}$ & $\begin{array}{c}4.4572 \\
4.4572,5.929 \\
90,90,120\end{array}$ & P3_121 (152) \\
\hline SbSel & $\begin{array}{c}9.164,4.187 \\
11.101\end{array}$ & $\begin{array}{c}90.0,90.0 \\
90.0\end{array}$ & 62 & Pnma & 31292,35470 & $\begin{array}{c}8.6862 \\
10.3927 \\
4.1452, \\
90,90,90\end{array}$ & Pnma (62) \\
\hline $\mathrm{PdBr}_{2}$ & $\begin{array}{c}12.871 \\
3.739,6.631\end{array}$ & $\begin{array}{c}90.0 \\
101.446 \\
90.0\end{array}$ & 15 & $\mathrm{C} 2 / \mathrm{c}$ & 27443 & $\begin{array}{c}6.59,3.96 \\
25.22,90 \\
92.6,90\end{array}$ & P2_1/c (14) \\
\hline
\end{tabular}




\begin{tabular}{|c|c|c|c|c|c|c|c|}
\hline BiSel & $\begin{array}{c}8.872,4.27, \\
10.695\end{array}$ & $\begin{array}{c}90.0,90.0, \\
90.0\end{array}$ & 62 & Pnma & $\begin{array}{c}280311, \\
163218\end{array}$ & $\begin{array}{c}8.6967, \\
4.2205, \\
10.574, \\
90,90,90\end{array}$ & Pnma (62) \\
\hline BiSI & $\begin{array}{c}8.670,4.214, \\
10.387\end{array}$ & $\begin{array}{c}90.0,90.0, \\
90.0\end{array}$ & 62 & Pnma & 25575,23631 & $\begin{array}{c}8.46,10.15 . \\
4.14, \\
90,90,90\end{array}$ & Pnma (62) \\
\hline $\mathrm{PNF}_{2}$ & $\begin{array}{c}8.611,5.387, \\
4.961\end{array}$ & $\begin{array}{c}90.0,90.0, \\
90.0\end{array}$ & 36 & Cmc2_1 & 9684 & $\begin{array}{c}8.69,5.38, \\
4.86,90,90, \\
90\end{array}$ & Cmc2_1(36) \\
\hline
\end{tabular}

(a)

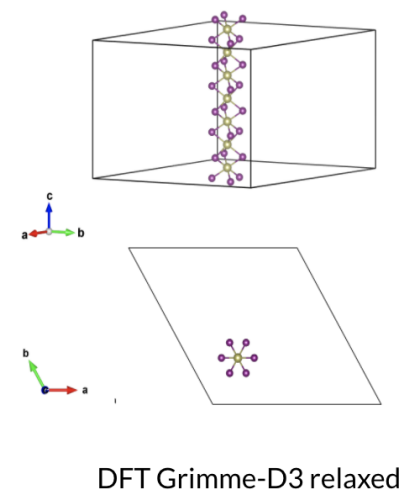

$\mathrm{Hfl}_{3}$
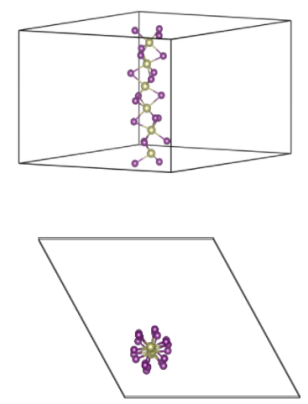

DFT-MD (b)
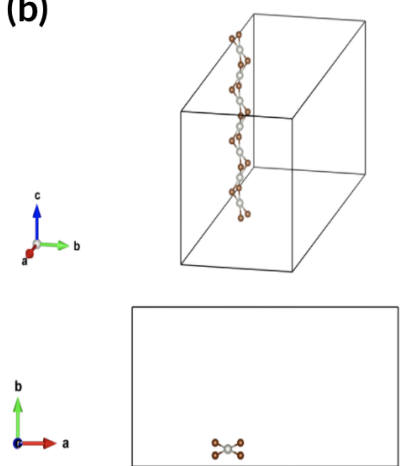

DFT Grimme-D3 relaxed
$\mathrm{PdBr}_{2}$
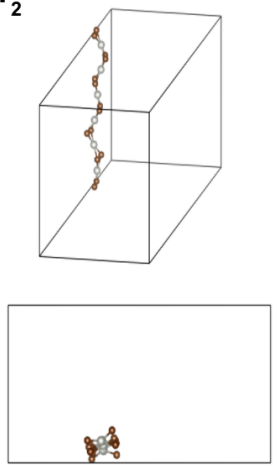

DFT-MD

SI Figure 6. The DFT Grimme-D3 relaxed structures and the resulting DFT-MD structures taken at room temperature are shown for $\mathrm{Hfl}_{3}(\mathrm{a})$ and $\mathrm{PdBr}_{2}$ (b). Calculations were completed using 3 primitive unit cells in the wire direction to account for possible distortions. The calculations reveal no disintegration of the wire structure, suggesting mechanical stability in the $1 \mathrm{D}$ form. 


\section{References}

[1] Mounet, N., Gibertini, M., Schwaller, P., Campi, D., Merkys, A., Marrazzo, A., Sohier, T., Castelli, I.E., Cepellotti, A., Pizzi, G. and Marzari, N.,, Two-Dimensional Materials from High-Throughput Computational Exfoliation of Experimentally Known Compounds, Nature Nanotechnology. 2018, 13, 246-252

[2] Curtarolo, S., Setyawan, W., Hart, G.L., Jahnatek, M., Chepulskii, R.V., Taylor, R.H., Wang, S., Xue, J., Yang, K., Levy, O. and Mehl, M.J., AFLOW: An Automatic Framework for High-Throughput Materials Discovery. Computational Materials Science. 2012, 58, 218-226.

http://aflowlib.org/aflow-online/ (Accessed February, 2021)

[3] Bergerhoff, G., Hundt R., Sievers R., and Brown I.D., The Inorganic Crystal Structure Database, Journal of Chemical Information and Computer Sciences. 1983, 23, 66-69 https://www.fiz-karlsruhe.de/en/produkte-und-dienstleistungen/inorganic-crystal-structuredatabase-icsd (Accessed February, 2021) 